\title{
Research on the influence of parameters on hexafluoropropylene oxide oli- gomerization in the presence of complex amines
}

\author{
Egbert Meissner, Agnieszka Wróblewska \\ Szczecin University of Technology, Institute of Organic Chemical Technology, ul. Pułaskiego 10, 70-322 Szczecin, Poland, \\ e-mail: Egbert.Meissner@ps.pl
}

\begin{abstract}
Oligomers of hexafluoropropylene oxide were tested as potential materials for obtaining vari-ous compounds with unique properties, of which most important are chemical and thermal re-sistance. Two basic parameters influence the oligomerization process of hexafluoropropylene oxide: the type of the catalyst and the type of the solvent. Other parameters such as temperature and pressure have significantly less influence. The influence of tertiary amines as catalyst, the type of the solvent, temperature, pressure and catalyst concentration were tested in the process of hexafluoropropylene oxide oligomerization.
\end{abstract}

Keywords: hexafluoropropylene oxide, oligomers of hexafluoropropylene oxide.

Presented at VII Conference Wasteless Technologies and Waste Management in Chemical Industry and Agriculture, Międzyzdroje, 12 - 15 June, 2007.

\section{INTRODUCTION}

Oligomers possessing a structure of a linear polyether terminated with fluorocarbonyl group are the products of hexafluoropropylene oxide oligomerization ${ }^{\mathbf{1}-\mathbf{3}}$ :

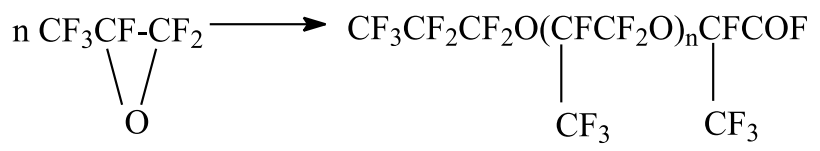

where: $\mathrm{n}$ can have values $0-10$

Hexafluoropropylene oxide (HFPO) is very sensitive to nucleophilic agents. It reacts with strong nucleophiles even below ambient temperature. The attack takes place generally on car-bon C3 (more substituted), but rarely on carbon $\mathrm{C} 2$. Halogens can be substituted with tertiary, secondary amines and enamines as the nucleophilic agents. The first stage of oligomerization is the izomerization of THFP to fluoride pentafluoropropione acid:
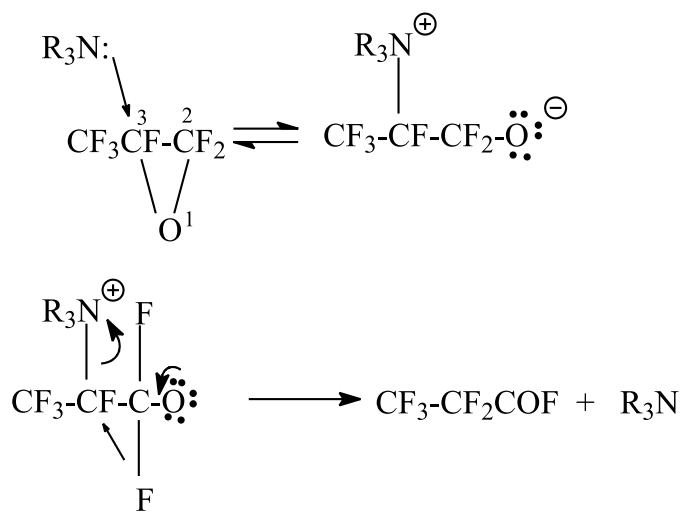

Fluoride pentafluoropropione acid is in equlibrium with heptafluoropropanol ion, which reacts with the HFPO molecule to obtain an alkoxy compound $(n=1)$. On elimination of the fluoride ion, the alkoxy compound is transformed into an acidic fluoride:

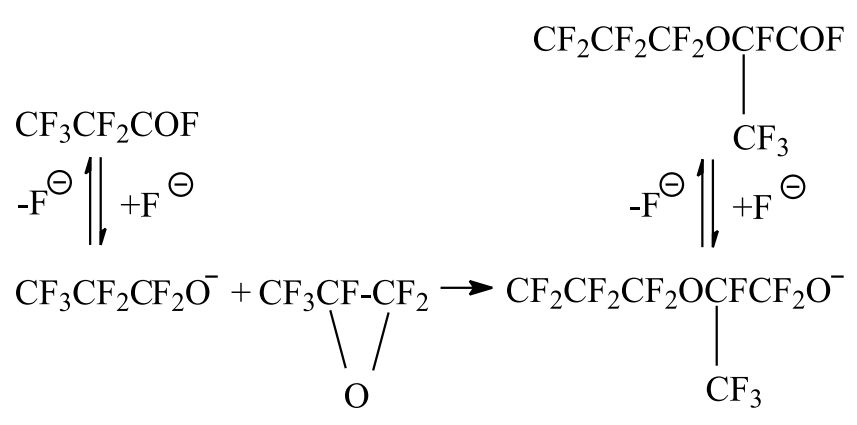

Attaching (HFPO) can be continued ( $n>1)$. The degree of oligomerization depends on the kind of the catalyst, the reaction conditions and the transparency of the HFPO. Oligomerization can lead to obtaining dimers of HFPO (perfluoro-2-n-propoxypropionic fluoride, $n=1$ ) with the maximum yield, which, after the transformation into alkali metal salts are pyrolysed, obtaining the technically interesting co-monomer in the form of a perfluoropropylvinyl ether. Trimers and tetramers of the HFPO are important intermediates in the synthesis of surface active agents with oleophobic polifluorinated chain, which should be especially emphasized, due to their unique useful properties. Higher HFPO oligomers were used as oils, which are thermostable and are chemically resistant.

The reason for undertaking the topic of HFPO oligomerization is the high applicability of the polyfluorinated surface active agents, their high value and rather small availability in the home market. The aim of this work was to examine the usefulness of oligomerization catalysts in the form of tertiary amines, for the purpose of obtaining trimers and tetramers of HFPO with the maximum yield. The length of the oleofobic fluoroorganic chain corresponding to a trimer and tetramer has the best surface properties.

\section{EXPERIMENTAL}

The scheme of an apparatus for the oligomerization of the HFPO is presented in Fig. 1. The oligomerization process was performed in a glass reactor (1) of the capacity of $250 \mathrm{~cm}^{3}$ fitted with a thermostative jacket. A certain 


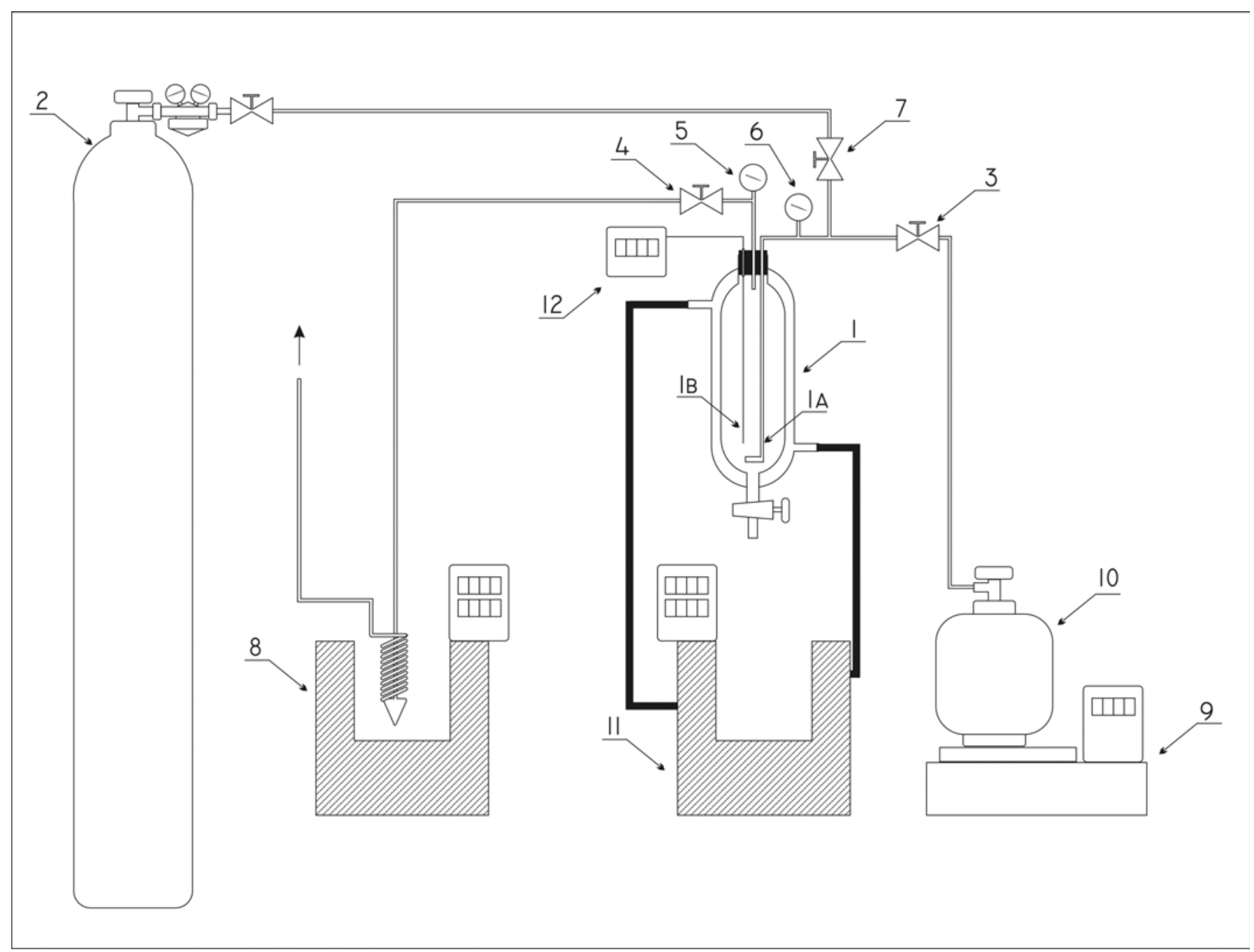

Figure 1. The scheme of the apparatus for the oligomerization of the HFPO

and constant temperature in the range of -10 to $+25^{\circ} \mathrm{C}$ was maintained by a cryostat (9). The glass reactor was fitted with a bubbler, whose task was to distribute the HFPO from under the surface of the liquid (1a), the thermocouple (1b), the needle valves to maintain constant pressure in the reactor (3 and 4), manometers (5 and 6). Additionally, the apparatus was fitted with a device to measure the temperature (12) as well as a nitrogen container (flask) (2). The gaseous HFPO was supplied into the reactor from a storage bottle (10), which was placed on a scale (9). The amount of the HFPO supplied was established by an observation of the loss of weight. The unreacted HFPO and HFP gases were removed at $40^{\circ} \mathrm{C}$ (8). The $30 \mathrm{~cm}^{3}$ of the previously dried acetonitrile and $5 \mathrm{~cm}^{3}$ adequate amine (catalyst) were poured into a dry reactor. After achieving constant temperature, $30 \mathrm{~g}$ of the HFPO was fed at such a rate that a constant pressure could be maintained. At the end of the reaction, the contents of the reactor (two liquid phases) were placed into a dry flask and weighed. The product of the oligomeriza- tion was later estrificated with methyl alcohol. The oligomerization products were analysed as methyl esters on a Chrom 5 gas chromatograph equipped with a $7 \mathrm{~m}$ column of $3 \mathrm{~mm}$ diameter packed with Reoplex 100 on a chromosorb WAW 60/80 mesh. The analysis conditions: initial $50^{\circ} \mathrm{C}$ for 4 minutes and then an increase from 50 to $200^{\circ} \mathrm{C}$ at $20^{\circ} \mathrm{C} /$ minute, detector FID, carrier gas nitrogen $25 \mathrm{~cm}^{3} /$ minute, volume of sample $0.3 \mu \mathrm{l}$.

\section{RESULTS}

The influence of the kind of the catalyst was investigated under the following condi-tions: the temperature 20 $-25^{\circ} \mathrm{C}$, pressure 2 at, the amount of the solvent (acetonitrile) $30 \mathrm{~cm}^{3}$, the reaction time $60 \mathrm{~min}$ and the molar concentration of the catalyst in the ratio to HFPO $=1: 10$. The obtained results are presented in Table 1.

The influence of pressure was investigated under the following constant conditions: catalyst (N,N,N',N'Tetramethylethylenediamine) and its molar concentration

Table 1. The dependence of the selectivity of the HFPO oligomerization on the kind of the catalyst

\begin{tabular}{|c|c|c|c|c|c|c|}
\hline & \multirow{2}{*}{ Amine } & \multicolumn{4}{|c|}{ [wt \%] } & \multirow{2}{*}{$\begin{array}{l}\text { Conversion of } \\
\text { HFPO [wt \%] }\end{array}$} \\
\hline & & $\mathrm{n}=0$ & $\mathrm{n}=1$ & $n=2$ & $\mathrm{n} \geq 3$ & \\
\hline 1. & Triethylamine & 51.0 & 47.0 & 2.0 & - & 54.6 \\
\hline 2. & Tributylamine & 43.5 & 58.6 & 3.7 & 0.2 & 58.1 \\
\hline 3. & N,N,N',N'-Tetramethylethylenediamine & 2.3 & 77.1 & 16.7 & 3.8 & 97.4 \\
\hline 4. & $\mathrm{~N}, \mathrm{~N}, \mathrm{~N}$ ',N'-Tetraethylethylenediamine & 2.6 & 81.0 & 16.6 & 2.4 & 96.5 \\
\hline 5. & N,N,N',N'-Tetramethy-1,6-hexanediamine & 1.8 & 52.6 & 39.0 & 6.5 & 100.0 \\
\hline 6. & 1,1'- Methylenebis (3-methylpiperidine) & 1.3 & 75.8 & 18.8 & 4.0 & 100.0 \\
\hline 7 & N.N'-Dimethylpiperazine & 1.7 & 73.7 & 23.3 & 1.2 & 98.1 \\
\hline
\end{tabular}


Table 2. The dependence of the selectivity of the HFPO oligomerization on pressure

\begin{tabular}{|l|c|c|c|c|c|c|}
\hline & Pressure & \multicolumn{4}{|c|}{$[\mathrm{wt} \%]$} & Conversion of \\
\cline { 3 - 6 } & {$[$ at] } & $\mathrm{n}=0$ & $\mathrm{n}=1$ & $\mathrm{n}=2$ & $\mathrm{n} \geq 3$ & HFPO [wt \%] \\
\hline 1. & 0.5 & 0.9 & 37.8 & 32.1 & 31.0 & 73.5 \\
\hline 2. & 2.0 & 0.0 & 19.9 & 38.8 & 41.3 & 100.0 \\
\hline
\end{tabular}

in the ratio to $\mathrm{HFPO}=1: 10$, the reaction time $60 \mathrm{~min}$, temperature $20-25^{\circ} \mathrm{C}$, solvent - acetonitrile $30 \mathrm{~cm}^{3}$. The reaction results are presented in Table 2 .

The influence of the solvent was investigated under the following constant conditions: catalyst $\left(\mathrm{N}, \mathrm{N}, \mathrm{N}^{\prime}, \mathrm{N}^{\prime}-\right.$ Tetramethylethylenediamine) and its molar concentration in the ratio to $\mathrm{HFPO}=1: 10$, the reaction time $60 \mathrm{~min}$, the temperature of the process $20-25^{\circ} \mathrm{C}$, pressure 2 at. The obtained results are presented in Table 3.

Table 3. The dependence of the selectivity of the HFPO oligomerization on pressure

\begin{tabular}{|l|l|l|l|l|l|c|}
\hline \multirow{2}{*}{} & Solvent & $\mathrm{n}=0$ & $\mathrm{n}=1$ & $\mathrm{n}=2$ & $\mathrm{n} \geq 3$ & $\begin{array}{c}\text { Conversion } \\
\text { of } \\
\text { HFPO } \\
{[\mathrm{wt} \%]}\end{array}$ \\
\hline 1. & Tetrahydrofuran & 5.3 & 63.1 & 28.1 & 3.5 & 68.4 \\
\hline 2. & Acetonitrile & 0.0 & 19.9 & 38.8 & 41.3 & 100.0 \\
\hline
\end{tabular}

The influence of the catalyst concentration was investigated under the following con-stant conditions: catalyst $\left(\mathrm{N}, \mathrm{N}, \mathrm{N}^{\prime}, \mathrm{N}^{\prime}-\right.$ Tetramethylethylenediamine) and its molar concentration in the ratio to $\mathrm{HFPO}=1: 10$, the reaction time $60 \mathrm{~min}$, the amount of the solvent (acetonitrile) $30 \mathrm{~cm}^{3}$, temperature $20-25^{\circ} \mathrm{C}$, pressure 2 at. The obtained results are presented in Table 4.

The influence of the temperature was investigated under the following constant conditions: catalyst (N,N,N',N'Tetramethylethylenediamine) and its molar concentration in the ratio to HFPO $=1: 10$, the amount of the solvent (acetonitrile) $30 \mathrm{~cm}^{3}$, the reaction time $120 \mathrm{~min}$, pressure 0.5 at. The obtained results are presented in Table 5.

\section{CONCLUSION}

Most of the tertiary amines tested turned out to be good HFPO oligomerization catalysts. As shown in Table 1, tetriary simple amines: triethylo- and tributyloamine are less active catalysts. The conversion of the HFPO after 1 hour of reaction in the case of simple amines is in the range $54-58 \mathrm{wt} \%$ in the proportion to the inserted oxide. However, the conversion of HFPO under similar conditions for the complex amines is in the range of 96 to100 wt $\%$. Not only is the conversion of oxide higher for the complex amines, but also the composition of oligomers is more useful for tertiary amines, because trimers and tetramers useful in the synthesis of surface active compounds are formed. Another tested parameter (Table 2) is the influence of pressure on the HFPO oligomerization. An increase in pressure from 0.5 to 2 at causes an increase in the HFPO conversion from 73.5 to $100.0 \mathrm{wt} \%$ and a rise in the content of heavy oligomers $(n \geq 3)$. An important parameter of oligomerization is the influence of the solvent, Table 3. As it can be observed in Table 3, a polar protic solvent such as acetonitrile significantly influences the conversion of oxide as well as the composition of Oligomers in compari-son to a less polar solvent such as THF. The molar concentration of the catalyst (Table 4) ranging from 1:10 to 1:20 has a little influence on the HFPO conversion, but more on the composition of oligomers, the higher the concentration of the catalyst is, the higher the concentration of heavy oligomers $(n \geq$ 3 ) gets. Temperatures (Table 5) in the range -10 to $23^{\circ} \mathrm{C}$ influence both the conversion and the composition of Oligomers. At $-10^{\circ} \mathrm{C}$, the conversion of the oxide attains $45 \mathrm{wt} \%$ in relation to the inserted HFPO, and the main product of the oligomerization is a dimmer. However, at $23^{\circ} \mathrm{C}$, the conversion of the HFPO reaches $100 \mathrm{wt} \%$ and the main products are oligomers with $n \geq 3$.

In conclusion, it can be confirmed that complex tetriary amines are good catalysts for the HFPO oligomerization. The advantage of tertiary amines is that they are not sensitive to humidity as compared to the catalysts such as alkaline metal halides. This makes the work with amines much easier.

\section{LITERATURE CITED}

(1) Millauer H., Schwertfleger W., Siegemund G,: Hexafluoropropylene oxide - a key compound in organofluorine chemistry, Angew. Chem. Int. Ed. Engl. 1985, 24, 161.

(2) Strutz $\mathrm{H}$ at al.: Method for the oligomerization of hexafluoropropene oxide, EP 0378797, 1990.

(3) Darling D.T. at al.: Polymerization of hexafluoropropylene oxide, EP 0154297, 1985.

Table 4. The dependence of the selectivity of the HFPO oligomerization on the catalyst concentration

\begin{tabular}{|l|l|c|c|c|c|c|}
\hline & \multirow{2}{*}{ The molar ratio catalyst/HFPO } & \multicolumn{3}{|c|}{$[\mathrm{wt} \%]$} & \multicolumn{2}{c|}{$\begin{array}{c}\text { Conversion of } \\
\text { HFPO [wt \%] }\end{array}$} \\
\cline { 3 - 7 } & & $\mathrm{n}=0$ & $\mathrm{n}=1$ & $\mathrm{n}=2$ & $\mathrm{n} \geq 3$ & 100 \\
\hline 1. & $1: 10$ & 0.0 & 19.9 & 38.8 & 41.3 & 100.0 \\
\hline 2. & $1: 20$ & 0.8 & 56.0 & 40.2 & 3.0 & 100.0 \\
\hline
\end{tabular}

Table 5. The dependence of the selectivity of the HFPO oligomerization on the temperature of the process

\begin{tabular}{|c|c|c|c|c|c|c|}
\hline & \multirow{2}{*}{$\begin{array}{l}\text { Temperature } \\
{\left[{ }^{\circ} \mathrm{C}\right]}\end{array}$} & \multicolumn{4}{|c|}{ [wt \%] } & \multirow{2}{*}{$\begin{array}{l}\text { Conversion of } \\
\text { HFPO [wt \%] }\end{array}$} \\
\hline & & $n=0$ & $n=1$ & $n=2$ & $n \geq 3$ & \\
\hline 1. & -10 & 38.5 & 58.2 & 3.3 & - & 45.0 \\
\hline 2. & 23 & 0.0 & 19.9 & 38.8 & 41.3 & 100.0 \\
\hline
\end{tabular}

